\title{
Efficacy of an enzyme-linked immunosorbent assay as a diagnostic tool for schistosomiasis mansoni in individuals with low worm burden
}

\author{
Edward José de 0 liveira/ ${ }^{+}$, Hermínia Yohko Kanamura/*, Dirce Mary Correia Lima**
}

Departamento de Análises Clínicas, Faculdade de Ciências Farmacêuticas, Universidade de São Paulo, Av. Prof. Lineu Prestes 580, Cj. das Químicas Bloco 17, 05315-970 São Paulo, SP, Brasil *Departamento de Biologia, Universidade de Taubaté, Taubaté, SP,

Brasil **Laboratório de Investigação Médica (LIM06), Instituto de Medicina Tropical de São Paulo, São Paulo, SP, Brasil

IgM-ELISA is an immunoenzymatic method useful for detection of IgM antibodies against a fraction of Schistosoma mansoni adult worm antigen (AWA) that is soluble in trichloroacetic acid (AWA-TCA). This method was applied to three groups of individuals with different clinical and epidemiological characteristics, and the results compared with those obtained by other diagnostic methods: immunofluorescence test for detection of IgM antibodies (IgM-IFT) or IgG antibodies (IgG-IFT), ELISA for detection of IgG antibodies (IgG-ELISA), and two parasitological methods, Kato-Katz and miracidium hatching. The IgM-ELISA presented a sensitivity of 98\%, when the parasitologic fecal examination was defined as reference diagnostic method, and a specificity of 98 and $97.3 \%$, respectively for the group of clinically healthy individuals and other helminth carriers. A comparative analysis between the results of IgM-ELISA and those obtained by other serologic tests showed a good degree of agreement, with Kappa indices ranging from 0.95 to 0.98. The diagnostic efficacy of $97.8 \%$, as determined with schistosomiasis patients with low parasitic burden, suggests the excellent performance of the IgM-ELISA and its usefulness for the diagnosis of schistosomiasis when applied in low endemic areas.

Key words: Schistosoma mansoni - immunodiagnosis - ELISA - IgM antibodies

Laboratory diagnosis of schistosomiasis mansoni is generally performed by fecal parasitologic methods and one of the most frequently used in field studies is the Kato-Katz technique (Katz et al. 1972). Nevertheless, it is already known the poor diagnostic efficiency of this method when applied to individuals with low worm burden (De Vlas \& Gryssels 1992, Eltiro et al. 1992, Engels et al. 1996, Noya et al. 1999), particularly in epidemiological studies where only one fecal sample per individual is examined. Hence, alternative laboratory diagnostic methods are under evaluation for use in schistosomiasis control programs of low endemic areas. Epidemiological studies carried out in some schistosomiasis endemic areas in the state of Sao Paulo, Brazil, have tested different antigen preparations on the indirect immunofluorescence test (IFT), such as: particles of schistosome adult worm antigen (Dias et al. 1971), liver fractions containing egg granuloma (Kawazoe et al. 1981), adult worm frozen sections (Dias et al. 1992a), and worm paraffin sections, the last one for detection of IgM antibodies against gut-associated antigens (IgM-IFT) (Kanamura et al. 1998b, Lima et al. 1998).

Good rates of sensitivity for diagnosis of both, acute and chronic schistosomiasis, have been demonstrated by

Financial partial support: Fapesp, grant 97/13904-0

+Corresponding author. E-mail: edwardjo@usp.br

Received 31 August 2004

Accepted 21 June 2005
IgM-IFT; and also good specificity was observed when this test was applied in a schoolchildren population with high prevalence for helminth infection, such as ascaridiasis, trichuriasis, and enterobiasis, but no schistosomiasis (Silva et al. 1992, Kanamura et al. 1998a, 2002). However, this technique involves the need of a microscope equipped with a fluorescent lamp and subjective reading of results, rendering difficult its use in more extensive epidemiological studies.

Therefore, researches have been conducted to produce specific antigens that have desirable indices of sensitivity and specificity for use in ELISA, since this technique is better adapted to large scale laboratory diagnosis of schistosomiasis in automated and quantitative assays (Sathe et al. 1991, Eltiro et al. 1992, Doenhoff et al. 1993, Kamal et al. 1994, Valli et al. 1997). When the results obtained by an ELISA for detection of $\operatorname{IgG}$ antibodies against a crude adult worm antigen preparation (IgGELISA) were compared with those obtained by the IgMIFT, in a schoolchildren population living in a low endemic area, poor index of concordance was observed, better diagnostic efficiency being observed for the IgMIFT (Silva et al. 1998). The use of a polysaccharide fraction of the S. mansoni adult worm antigen preparation, soluble in trichloroacetic acid (TCA-soluble fraction), as antigenic substrate in a ELISA method, for detection of IgM antibodies (IgM-ELISA) was evaluated by Oliveira et al. (2003), in a region of low endemicity for schistosomiasis, showing good degree of concordance when compared to IgM-IFT.

In this paper, further evaluation of the IgM-ELISA was performed on groups of patients with different clinical and epidemiological characteristics. 


\section{MATERIALS AND METHODS}

Serum samples - Group A: obtained from 50 schistosomiasis patients, parasitologically confirmed by KatoKatz and/or miracidium hatching method, with $S$. mansoni egg counts varying from 8 to 320 epg (eggs per gram of feces), selected from the serum bank maintained by the Institute of Tropical Medicine of São Paulo (ITMSP); Group B: from 50 clinically healthy individuals without $S$. mansoni eggs in the fecal examination, selected from the serum bank of ITMSP; Group C: from 37 individuals living in a locality that was non-endemic for schistosomiasis according to Sucen (Superintendência de Controle de Endemias of the Health Department of São Paulo State Government), but infected with parasitic species other than S. mansoni. The use of those samples received the approval of the Committee for Ethics in Research of the Institute of Tropical Medicine of São Paulo of the University of São Paulo.

Stool examination - The Kato-Katz method was used for parasitological examination, preparing three slides for each stool sample; S. mansoni egg counts were expressed in epg, using the arithmetic mean of egg counts obtained from three slides, multiplied by 24 (Katz et al. 1972). KatoKatz negative samples were also submitted to the miracidium hatching method, as follows. Two grams of feces were homogenized in distilled water and then filtered over double layer gauze to remove larger detritus, repeating the filtration until a clear supernatant liquid was obtained. This suspension was then transferred to a volumetric flask and exposed to light, to check the presence of moving miracidium in the supernatant, which can be done with the naked eye, or by means of a magnifying glass. A commercial system, Coprotest ${ }^{\circledR}$ (Cerqueira 1988), was also used to examine the stool samples of the Group C, preparing two slides for each fecal sample.

IgM-ELISA - TCA-soluble fraction of the S. mansoni adult worm antigen preparation was obtained as described earlier (Deelder \& Kornelis 1980) and used as antigen for coating flat polystyrene plates (Nunc, Brand Products, Denmark), according to previous standardization (Oliveira et al. 2003). Test sera diluted 1:100 in PBS-Tween-milk (phosphate buffered solution containing $0.05 \%$ of Tween20 and $1 \%$ skimmed milk) were incubated for $1 \mathrm{~h}$ at $37^{\circ} \mathrm{C}$. After washings, peroxidase-conjugated anti-human IgM (Sigma Chemical Company, St Louis, US) diluted to 1:4.000 was added and incubated for $1 \mathrm{~h}$ at $37^{\circ} \mathrm{C}$. After another series of washings, a chromogenic mixture of $\mathrm{H}_{2} \mathrm{O}_{2}$ and OPD (o-phenylenediamine) was added. After $30 \mathrm{~min}$ in the dark and addition of stop solution $\left(\mathrm{H}_{2} \mathrm{SO}_{4} 1 \mathrm{~N}\right)$, the optical density (OD) was measured at $492 \mathrm{~nm}$, in a microplate reader (SLT-Labinstruments-Spectra I). The test samples were assayed in triplicate, and for each reaction day, serial dilution of a positive control serum, in duplicate, were added, and the cutoff value was determined calculating the arithmetic mean of the OD readings of eight negative control sera diluted to $1: 100$, plus two or three standard deviations.

IgG-ELISA - For this test, polystyrene plates were coated with crude adult worm antigen, according to meth- odology described elsewhere (Valli et al. 1997). Test sera were diluted 1:100 in PBS-Tween-milk and peroxidase conjugated anti-human $\operatorname{IgG}$ (Sigma) was diluted to 1:4.000, following the procedure used for IgM-ELISA.

Immunofluorescence test for detection of $\mathrm{Ig} G$ and $\mathrm{IgM}$ antibodies (IgG-IFT, IgM-IFT) - The IgG-IFT on frozen sections of worms included in Tissue-Tek ${ }^{\circledR}$ (Miles Scientific, Indiana, US) was used to examine the serum samples diluted to 1:10, in duplicate, as already described (Dias et al. 1992). The immunofluorescence test for detection of IgM antibodies against gut-associated antigens (IgMIFT) was performed on paraffin sections of S. mansoni worms treated with Rossman's solution, with serum samples diluted to 1:40, as described (Silva et al. 1992). The anti-human IgG and IgM fluorescent conjugates (Biolab, Rio de Janeiro, Brazil) were used according to their optimum titers, determined by block titration against positive and negative control sera. The slides were read at an Olympus BX-FLA fluorescent microscope equipped with a 100W mercury lamp and an excitation filter BP 450480 with a 100 magnifying power. The samples were defined as positive for IgG-IFT when presented fluorescence in the parenchyma and/or gut of the worms, and for IgMIFT, when presented fluorescence in the gut of the worms.

Statistical analysis - The comparative analysis for the performance of the different diagnostic methods, calculating sensitivity, specificity, and concordance indices, were done using the statistical package of EPI-INFO 6.04 version (Dean et al. 1995).

\section{RESULTS}

All the patients from Group A had their S. mansoni infection confirmed by fecal examination, 49 by Kato-Katz and one by miracidium hatching method, this last patient being negative by Kato-Katz. According to WHO (1997), the majority of them can be classified as light infestation, with egg counts less than $100 \mathrm{epg}$, varying from 8 to 96, with geometric mean of $21.7 \mathrm{epg}$. Six individuals can be classified as moderate infestation with egg counts ranging from 104 to 320 and geometric mean of $128.5 \mathrm{epg}$. In Group B, all individuals were confirmed to be negative for S. mansoni, when submitted to Kato-Katz and miracidium hatching method. The individuals of the Group C presented helminth species other than S. mansoni in their fecal examination, with positivity indices of $16.2 \%(6 / 37)$ for Ascaris lumbricoides, $10.8 \%$ (4/37) for Strongyloides stercoralis, $5.4 \%$ (2/37) for Trichuris trichiura, and 5.4\% (2/37) for mixed infestation, A. lumbricoides and $T$. trichiura.

In a preliminary experiment, for the interpretation of the IgM-ELISA results, two criteria were evaluated: (C1) and (C2), defining as cutoff values the arithmetic mean plus two or three standard deviations, respectively. For the 50 schistosomiasis confirmed patients of Group A, regardless of $\mathrm{C} 1$ or $\mathrm{C} 2$ criteria, 49 samples were positives, providing a sensitivity index of $98 \%$ (Table I). However, when the two cutoff criteria were evaluated on S. mansoni negative groups, better results were obtained with the second criterion (C2), the specificity of the test being compromised if the first criterion $(\mathrm{C} 1)$ was adopted. On the 
basis in these preliminary results, the cutoff value for IgMELISA was defined as mean plus three standard deviations.

According to the data on Table I, as determined for the Group A, composed by 50 schistosomiasis confirmed patients, the sensitivity of IgM-ELISA was comparable to IgM-IFT (98\%), but lower than the value obtained for IgGIFT (100\%). The specificity of IgM-ELISA was also good, with only two false positive results in 87 non schistosomiasis individuals, one among the 50 clinically healthy individuals of Group B and one on 37 individuals of Group $\mathrm{C}$, giving a specificity index of $97.7 \%$ (85/87).

The comparative analysis between the results of IgMELISA and those obtained by other immunological methods, on the total of 137 studied samples, showed an almost perfect degree of agreement, with Kappa indices ranging from 0.95 to 0.98 (Table II).

If the criterion for true schistosomiasis was defined as presence of $S$. mansoni eggs in the fecal examination, we can classify the 137 studied samples as 50 schistosomiasis and 87 non schistosomiasis. According to this criterion, the diagnostic indices for IgM-ELISA were defined as follow: sensitivity of $98 \%$, specificity of $97.7 \%$, and diagnostic efficacy of $97.8 \%$ (Table III).

\section{DISCUSSION}

This study was undertaken with the aim of assessing the performance of IgM-ELISA for diagnosis of schistosomiasis. Three groups of individuals with different clinical and epidemiological characteristics were submitted to this test and the results compared to the fecal parasitologic methods and other serological tests (IgM-IFT, IgG-
TABLE III

Diagnostic parameters for IgM-ELISA obtained on results of 137 serum samples employed in this study

\begin{tabular}{lccc}
\hline ELISA-IgM & Schistosomiasis & No schistosomiasis & Total \\
\hline Positive & 49 & 2 & 51 \\
Negative & 1 & 85 & 86 \\
Total & 50 & 87 & 137 \\
\hline
\end{tabular}

Criterion for schistosomiasis: fecal examination positive for Schistosoma mansoni eggs; Criterion for no schistosomiasis: fecal examination negative for S. mansoni eggs; Sensitivity: $98 \%$ (49/50); Specificity: $97.7 \%$ (85/87); Efficacy: 97.8\% (49+85/ 137).

IFT, IgG-ELISA). For the interpretation of the results of IgM-ELISA two criteria were evaluated: (C1) or (C2) defining as cutoff values the arithmetic mean of the OD readings of eight negative control sera diluted to 1:100, plus respectively two or three standard deviations. Since better specificity was obtained with the $\mathrm{C} 2$ criterion, without loss of sensitivity, the cutoff value for IgM-ELISA was defined as mean plus three standard deviations.

The sensitivity of IgM-ELISA was $98 \%$, determined with the 50 parasitologically confirmed schistosomiasis patients on Group A. The unique sample on this group, with an egg count of $16 \mathrm{epg}$, which was negative for ELISAIgM was also negative for IgM-IFT, but positive for IgGELISA and IgG-IFT. An excellent specificity of $98 \%$ was observed when tested among the 50 clinically healthy individuals of Group B, with only one false positive result

TABLE I

Positivity rates obtained by the different immunological methods, according to the studied group

\begin{tabular}{|c|c|c|c|c|c|c|}
\hline \multirow[b]{3}{*}{ Immunological methods } & \multicolumn{6}{|c|}{ Number $(\mathrm{N})$ and percentage $(\%)$ of positive samples } \\
\hline & \multicolumn{2}{|c|}{$\begin{array}{c}\text { Group A } \\
\text { (n 50) }\end{array}$} & \multicolumn{2}{|c|}{$\begin{array}{c}\text { Group B } \\
(\mathrm{n} 50)\end{array}$} & \multicolumn{2}{|c|}{$\begin{array}{c}\text { Group C } \\
\text { (n 37) }\end{array}$} \\
\hline & $\mathrm{N}$ & $(\%)$ & $\mathrm{N}$ & $(\%)$ & $\mathrm{N}$ & $(\%)$ \\
\hline IgM-ELISA & 49 & $(98)$ & 1 & $(2)$ & 1 & $(2.7)$ \\
\hline IgM-IFT & 49 & (98) & 0 & $(0)$ & 1 & $(2.7)$ \\
\hline IgG-ELISA & 48 & (96) & 0 & $(0)$ & 1 & $(2.7)$ \\
\hline IgG-IFT & 50 & $(100)$ & 0 & $(0)$ & 1 & $(2.7)$ \\
\hline
\end{tabular}

Group A: positive for Schistosoma mansoni eggs by fecal examination; Group B: clinically healthy individuals, negative for $S$. mansoni eggs; Group C: negative for S. mansoni eggs, but with other parasitic infestations.

TABLE II

Comparative results of IgM-ELISA and other immunological methods applied on total of 137 studied serum samples

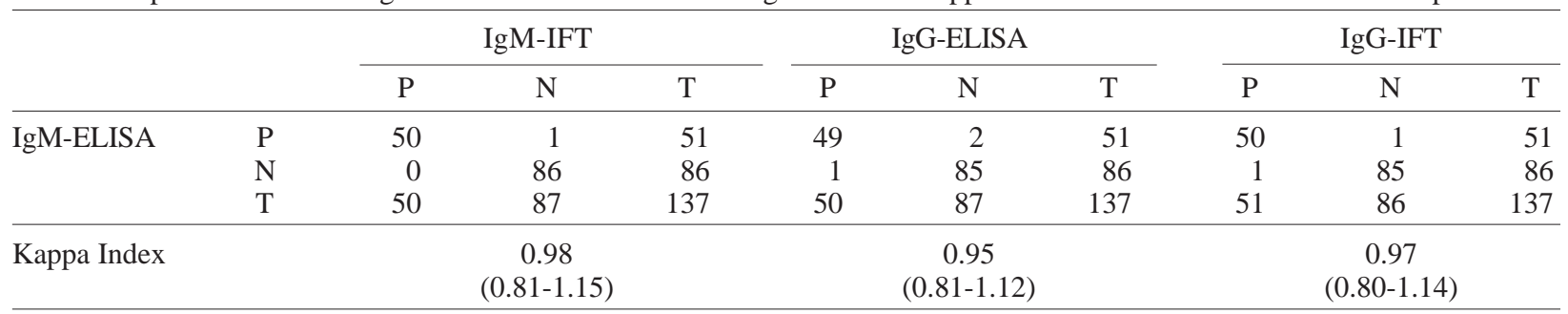

P: positive; N: negative; T: total; ( ) confidence interval with $95 \%$. 
for IgM-ELISA, this sample being also negative for other serological methods (Table I). In the Group C, composed by 37 individuals living in a region of high prevalence for other helminth parasites, one sample gave positive result for IgM-ELISA, and this unique sample was also positive for other serological tests (Table I), resulting in a specificity rate of $97.3 \%$, similar to that observed for IgM-IFT, as assessed in a schoolchildren population with high prevalence to A. lumbricoides, T. trichiura, and Enterobius vermiculares (Kanamura et al. 1998a). This result may suggest a very good specificity of IgM-ELISA, without cross reactivity with other helminth antigens, such as $A$. lumbricoides, $S$. stercoralis or T. trichiura, since the serological positivity index for schistosomiasis of $2.7 \%$ was lower than the positivity rates for the above mentioned parasite species, respectively $16.2,10.8$, and $4.4 \%$. The possible interference of rheumatoid factor and cross reactivity to A. lumbricoides was checked by searching for reactivity to latex test for rheumatoid factor and previous absorption of serum samples with Ascaris antigen. Other possibilities of serological positivity without detection of Schistosoma eggs should be kept in mind, such as unisexual infection, exposure to free living cercaria other than $S$. mansoni or contact with other closely related parasite species. Nevertheless, these serological positive results must be interpreted with criterion, taking into consideration other clinical, epidemiological, and laboratory criteria.

The egg counts of the parasitologically confirmed patients on Group A varied from 8 to 320 , with geometric mean of $31.2 \mathrm{epg}$. When the quantitative results of KatoKatz method were analyzed in comparison to the OD readings obtained by IgM-ELISA, a fragile correlation level $(\mathrm{R}=0.06)$ was observed, indicating no association between egg counts and IgM antibody levels by ELISA. In a previous paper, lack of association was also observed when egg counts were correlated to IgM antibody levels determined by IgM-IFT according to intensity of fluorescent reaction (Kanamura et al. 2002). These results showed that the determination of IgM antibody levels could not be an useful marker for classifying infection intensity in schistosomiasis.

The IgM-ELISA, as applied in this study, can be easily executed, presented good reproducibility and excellent diagnostic performance, representing an important tool for application in field studies, specially in low endemic areas for schistosomiasis.

\section{ACKNOWLEDGEMENTS}

To Maria Cristina Conceição de Mello for the maintenance of the $S$. mansoni cycle.

\section{REFERENCES}

Cerqueira FL 1988. Coprotest ${ }^{\circledR}$ : metodologia confiável para o exame parasitológico de fezes. LAES \& HAES 9: 5-12.

Dean AG, Dean JA, Coulombier D, Brendel KA, Smith D, Burton H, Dicker RC, Sullivan KM, Fargan RF, Arner TG 1995. Epi Info, Version 6: a word processing, database, and statistics program for public health on IBM-compatible microcomputers. Centers for Disease Control and Prevention, Atlanta, GA.
Deelder AM, Kornelis D 1980. A comparation of IFA an ELISA for the demonstration of antibody against schistosome gutassociated polysaccharide antigen in schistosomiasis. Zeitschrift fur Parasitendunde 64: 65-75.

De Vlas SJ, Gryssels B 1992. Underestimation of Schistosoma mansoni prevalences. Parasitol Today 8: 274-277.

Dias LCS, Camargo ME, Hoshino-Shimizu S, Ramos AA, Toledo Piza J, Silva LC 1971. Inquéritos populacionais de esquistosssomose mansoni por técnicas sorológicas de imunofluorescência e de hemaglutinação. Rev Inst Med Trop São Paulo 13: 37-44.

Dias LCS, Kanamura HY, Hoshino-Shimizu S, Glasser CM, Carvalho JF, Silva LC 1992. Field trials for immunodiagnosis with reference to Schistosoma mansoni. In NR Bergquist, Immunodiagnostic Approches in Schistosomiasis, John Wiley \& Sons, England, p. 39-47.

Doenhoff MJ, Butterworth AE, Hayes RJ, Sturrock RF, Ouma JH, Koech D, Prentice M, Bain J 1993. Seroepidemiology and serodiagnosis in Kenya using crude and purified egg antigens of Schistosoma mansoni in ELISA. Trans $R$ Soc Trop Med Hyg 87: 42-48.

Eltiro F, Ye-Ebiyo Y, Taylor MG 1992. Evaluation of an enzyme linked immunosorbent assay (ELISA) using Shistosoma mansoni soluble egg antigen as a diagnostic tool for Shistosoma mansoni Ethiopian schoolchildren. Am J Trop Med Hyg 98: 52-56.

Engels D, Sinzinkayo E, Gryseels B 1996. Day-to-day egg count fluctuation in Schistosoma mansoni infection and its operational implications. Am J Trop Med Hyg 54: 319-24.

Kamal KA, Shaheen HI, El-Said AA 1994. Applicability of ELISA on bufferr-eluates of capillary blood spotted on filter papers for the diagnosis and clinical staging of human schistosomiasis. Trop Geog Med 46: 138-141.

Kanamura HY, Dias LCS, Silva RM, Glasser CM, Patucci RMJ, Bellosa SAG, Antunes JLF 1998a. A comparative epidemiologic study of specific antibodies (IgM and $\operatorname{IgA}$ ) and parasitological findings in an endemic area of low transmission of Schistosoma mansoni. Rev Inst Med Trop São Paulo 40: 85-91.

Kanamura HY, Dias LCS, Glasser CM, Silva RM, Patucci RMJ, Chiodelli SG, Addiss DG 1998b. Detection of IgM antibodies to Schistosoma mansoni gut-associated antigens for the study of the dynamics of schistosomiasis transmission in na endemic area with low worm burden. Rev Inst Med Trop São Paulo 40: 225-231.

Kanamura HY, Silva RM, Chiodelli SG, Glasser CM, Dias LCS 2002. IgM-Immunofluorescence test as a diagnostic tool for epidemiologic studies of schistosomiasis in low endemic areas. Mem Inst Oswaldo Cruz 97: 485-489.

Katz N, Chaves A, Pellegrino J 1972. A simple device for quantitative stool thick smear technique in schistosomiasis mansoni. Rev Inst Med Trop São Paulo 14: 397-400.

Kawazoe U, Hoshino-Shimizu S, Correa NS, Silva LC, Pinto ACM, Camargo ME 1981. An immunoepidemiological study of schistosomiasis mansoni in Paraíba Valley, São Paulo, Brazil. Rev Inst Med Trop São Paulo 23: 36-40.

Lima VLC, Guercio VMF, Rangel O, Kanamura HY, Dias LCS 1998. Immunofluorescence test on Schistosoma mansoni worm paraffin sections (IgM-IFT) for the study of schisto- 
somiasis transmission in Campinas, São Paulo, Brazil. Mem Inst Oswaldo Cruz 93: 283-288.

Noya B A, Balzan C, Arteaga C, Cesari I, Noya O 1999. The last fifteen years of schistosomiasis in Venezuela: features and evolution. Mem Inst Oswaldo Cruz 94: 139-146.

Oliveira EJ, Kanamura HY, Dias LCS, Soares LCB, Lima DMC, Ciaravolho RMC 2003. ELISA-IgM para diagnóstico da esquistossomose mansoni em área de baixa endemicidade. Cad Saúde Pública 19: 255-261.

Sathe BD, Pandit CH, Chanderkar NG, Badade DC, Sengupta SR, Renapurkar DM 1991. Serodiagnosis of schistosomiasis by ELISA test in an endemic area of Gimvi Vilage, India. Am J Trop Med Hyg 94: 76-78.

Silva RM, Silva MIPG, Vellosa SAG, Kanamura HY 1992. Pesquisa de anticorpos IgM contra tubo digestivo do verme para diagnóstico da esquistossomose mansônica. Rev Bras
Pat Clín 28: 39-42.

Silva RM, Kanamura HY, Camargo ED, Chiodelli SG, Nakamura PM, Gargioni C, Vellosa SAG, Antunes JLF 1998. A comparative study on IgG-ELISA, IgM-IFT and Kato-Katz methods for epidemiological purposes in a low endemic area for schistosomiasis. Mem Inst Oswaldo Cruz 93: 279282.

Valli LCP, Kanamura HY, Silva RM, Silva MIPG, Vellosa SAG, Garcia ET 1997. Efficacy of an enzyme-linked immunosorbent assay in the diagnosis of and serologic distinction between acute and chronic Schistosoma mansoni infection. Am J Trop Med Hyg 53: 358-362.

WHO-World Health Organization 1997. Schistosomiasis inprogress 1995-1996: thirteenth programme report of the UNDP/World Bank/ WHO Special Programme for Research and Training Diseases, Geneva. 
